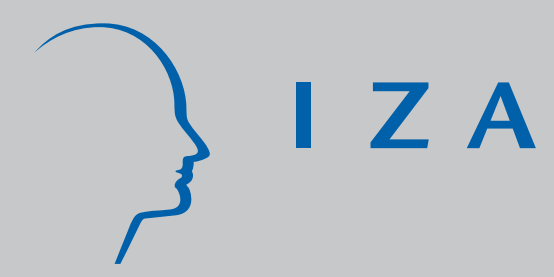

IZA DP No. 1633

A Search Model of Discouragement

Michael Rosholm

Ott Toomet

June 2005 


\title{
A Search Model of Discouragement
}

\author{
Michael Rosholm \\ University of Aarhus, AKF \\ and IZA Bonn \\ Ott Toomet \\ University of Aarhus and AKF
}

\section{Discussion Paper No. 1633 \\ June 2005}

\author{
IZA \\ P.O. Box 7240 \\ 53072 Bonn \\ Germany \\ Phone: +49-228-3894-0 \\ Fax: +49-228-3894-180 \\ Email: iza@iza.org
}

\begin{abstract}
Any opinions expressed here are those of the author(s) and not those of the institute. Research disseminated by IZA may include views on policy, but the institute itself takes no institutional policy positions.

The Institute for the Study of Labor (IZA) in Bonn is a local and virtual international research center and a place of communication between science, politics and business. IZA is an independent nonprofit company supported by Deutsche Post World Net. The center is associated with the University of Bonn and offers a stimulating research environment through its research networks, research support, and visitors and doctoral programs. IZA engages in (i) original and internationally competitive research in all fields of labor economics, (ii) development of policy concepts, and (iii) dissemination of research results and concepts to the interested public.
\end{abstract}

IZA Discussion Papers often represent preliminary work and are circulated to encourage discussion. Citation of such a paper should account for its provisional character. A revised version may be available directly from the author. 


\section{ABSTRACT}

\section{A Search Model of Discouragement}

Discouragement is a process occurring during an unemployment spell. As the spell prolongs, an individual gradually realises that the returns to search can no longer outweigh search costs, and hence she may eventually leave the labour force. This is analysed theoretically in a framework of unemployed search. We construct a search model, which is stationary from the point of view of the individual, but which has nonstationary features. Namely, the unemployed worker is occasionally hit by shocks leading to a decline in job offer arrival rates. These shocks can be due to stigmatisation or to psychological consequences of unemployement affecting search effectiveness. This model enables us to analyse the issue of discouragement, as the returns to search will gradually decline. Even so, the model is actually stationary from the point of view of the individual, which implies that many interesting theoretical results may be derived. Moreover, from the point of view of the researcher, the model exhibits negative duration dependence in the hazard rate into employment and positive duration dependence in the hazard rate into non-participation, features which correspond well to real data. We use the model to analyse theoretically the impact of changes in unemployment insurance and social assistance benefits, and we conduct some simulation exercises based on a calibrated model.

JEL Classification: J21, J64, J65

Keywords: labour supply, search theory, discouragement

Corresponding author:

Ott Toomet

School of Economics and Business Administration

Building 322

Århus University

8000 Århus C

Denmark

Email: otoomet@econ.au.dk

\footnotetext{
* We are grateful to Birthe Larsen, Rasmus Lentz and the participants of the Labour Day at Tinbergen Institute 2003 for their comments and suggestions. Remaining errors are ours.
} 


\section{Introduction}

The environment in which unemployed workers conduct job search is not stationary. Many studies in economics report changes in hazard rates out of unemployment as unemployment duration increases, and economists as well as psychologists and sociologists have shown that individual well-being is negatively related to unemployment, that well-being is declining with unemployment duration, and that decreasing well-being in turn has an impact on search behaviour $^{1}$. Some authors even note that the loss of confidence and self-esteem associated with the receipt of many rejections on job applications may have the rational consequence that it eventually becomes inoptimal for workers to continue searching (how better avoid rejections than by not applying). Therefore, workers may stop searching and thus leave the labour market altogether. This phenomenon is often referred to as discouragement.

The traditional stationary job search model can not deal with the issue of discouragement. Innately, discouragement is a dynamic process, which manifests itself only after some time in unemployment. For example, very few individuals make the transition directly from employment to non-participation, if we ignore maternity leave and retirement. Rather, persons spend some time in unemployment, and then they may eventually decide that it is no longer optimal to continue search, and only then do they leave the labour market.

The non-stationary search model, see e.g. van den Berg (1990a), is appropriate for dealing with this issue, and it has recently been extended by Frijters and van der Klaauw (2003) to allow for endogenous transitions out of the labour force. However, the model is quite complex; the reservation wage path is described by a first order differential equation without an analytical solution. For this reason, comparative statics are complicated, and estimation is even worse. Moreover, in the non-stationary search model, it is assumed that individuals know exactly the evolutions of all the crucial parameters over time. This seems a very strong assumption.

In this paper, we formulate a different type of search model which allows for endogenous transitions into non-participation. Technically, the model is completely stationary. However, certain parameters in the model are subject to unanticipated changes. Specifically, the job offer arrival rate is occasionally disturbed by Poissonian shocks. This leads to a falling average job offer arrival rate, while for every single individual, who observe the shocks, the situation is still stationary, in the sense that she does not anticipate any future changes in the model parameters. However, she expects that eventually her job offer arrival rate will fall through shocks. Moreover, allowing for endogenous exits from the labour force, the model predicts an increasing hazard rate into non-participation. These features of the theoretical model - declining unemployment-to-employment hazards and increasing unemployment-to-nonparticipation hazards - correspond to some empirical results on Danish unemployment durations, see e.g. Toomet (2005).

Frijters and van der Klaauw (2003) argue that since - empirically - transitions from unemployment into non-participation typically occur after some time in unemployment, the environment of the searching agent must be nonstationary. This is indeed the case, but as hinted at above, it does not mean that the

\footnotetext{
${ }^{1}$ The literature is not terribly clear on the issue of multiple directions of causality. See the survey of the relevant literature in the next section.
} 
complete paths of all model parameters are perfectly foreseen. In addition to deterministic paths, the parameters may be subjects to unanticipated events, e.g. due to rejections of job applications, stigma etc.

Atkinson and Micklewright (1991) note in their seminal paper on unemployment income that it is crucial to distinguish between several labour market states when one wants to analyse the impact of cuts in e.g. unemployment benefits $^{2}$. In this paper we analyze three types of 'benefit' cuts, one where only unemployment benefits are reduced, one where only social assistance (used here as a catch-all term for income transfers to non-participants, that is, those who decide to leave the labour market) is reduced, and one where there is a simultaneous reduction of unemployment benefits and social assistance. When only unemployment-benefits are cut, the result is a lower reservation wage, which leads to an increase in the hazard rate into employment. At the same time, however, the value of unemployment is reduced, which implies that unemployed workers leave the labour market faster. Hence, the transition rate into nonparticipation increases, too, when unemployment benefits are cut. Unemployment duration will certainly fall, but in this case that may not be a desirable policy outcome, if it is mainly driven by exits from the labour market. If only social assistance is lowered, "weak" unemployed individuals - those having received many shocks to the offer arrival rate - will stay in unemployment for a longer time period because the value of non-participation has fallen. This composition effect tends to lower the hazard rate into employment. However, as the value of unemployment falls as well (a second order effect derived from the decline in the value of non-participation), there is a counteracting tendency which increases the transition rate into employment. The overall effect is ambiguous, but this type of policy may well increase unemployment duration. In order to achieve the desired effect: low unemployment duration and a high participation rate, one has to adjust both types of benefits downwards simultaneously. In this case, the net effect of the policy will depend on the dosage chosen for each type of benefits. This issue is investigated - together with the two other policies - in a simple flow equilibrium model of the labour market, which embeds the search model specified in the paper, and which is calibrated to match some of the features characterizing flows in the Danish labour market.

The remainder of the paper is organised as follows: In the next section, we briefly review the search literature with a view towards papers dealing with issues related to discouragement, non-participation, and unemployment benefits. Section 3 contains a presentation of our model in which the job offer arrival rate is hit by shocks and there is disutility associated with unemployment. Section 4 investigates the impact of changes in economic incentives to search, including a small illustration by calibrating the model on Danish labour market flows. Section 5 discusses alternative specifications, and finally, further discussions and a conclusion are found in section 7 .

\footnotetext{
${ }^{2}$ This obviously holds more generally, since it is also necessary when analysing the full impacts of, say, active labour market policies.
} 


\section{Unemployment, Discouragement and Non- Participation: A Brief Review of the Related Literature}

In a seminal paper by Burdett, Kiefer, Mortensen, and Neumann (1984), the states occupied by individuals (employment, unemployment, or non-participation) are determined by utility flows and certain events. These events are stochastic shocks to the utility flows, they may be e.g. layoffs, job offers, or shocks to the individual utility function, which change the utility flow in any of the states. Upon the receipt of an event shock the individual chooses a new optimal labour market state. The arrival of events are described by stationary Poisson processes, which results in a three-state exponential duration model. Other studies have explicitly modelled search behaviour and reservation wages in unemployment while including the decision to become a non-participant as an exogenous event, see e.g. (van den Berg, 1990b). Frijters and van der Klaauw (2003) endogenize in a non-stationary framework the non-participation decision and thus explicitly model both the decision of whether to accept a job offer and whether to become a non-participant.

Empirical analyses have confirmed the importance of unemployment benefits on the hazard rate for leaving unemployment. There is a general agreement that higher benefits are related with lower exit rates out of unemployment (Bover, Arellano, and Bentolila, 2002; Addison and Portugal, 2003; Røed and Zhang, 2003). There is also evidence of a peak in the hazard rate around the date of benefit expiration (Meyer, 1990; Micklewright and Nagy, 1999; Røed and Zhang, 2003). However, in this paper we will abstract from the additional complications of a finite benefit period.

There is a broad consensus in the psychological literature that unemployment causes damage on the psychological health and well-being in general (Dooley, Fielding, and Levi, 1996). The source of the mental problems related to unemployment is not just low income (Theodossiou, 1998; Winkelmann and Winkelmann, 1998; Dooley, Prause, and Ham-Rowbottom, 2000). McFadyen and Thomas (1997) describe some insights and theories from social psychology. Motivation and problem solving abilities are disrupted during periods of unemployment, especially among the long-term unemployed. The implication is that job search will be adversely affected. The behaviour is rational; a rational strategy for coping with rejection is to avoid them (by not searching), thus avoiding further emotional disruption. It is even argued that psychological well-being may be (at least) partially restored by distancing oneself from work related matters, that is, by becoming a non-participant. However, there is not universal agreement about the psychological impact of non-participation relative to employment and unemployment. Theodossiou (1998) and Winkelmann and Winkelmann (1998) argue that unemployment is significantly worse than nonparticipation according to most of the indicators under study. On the contrary, according to Dooley, Prause, and Ham-Rowbottom (2000), non-participation is even larger cause of depression than unemployment. Goldsmith, Veum, and Darity, Jr. (1995) do not find any significant difference between those two labour market states. Unfortunately, the direct reasons for non-participation were not distinguished in any of these studies.

Not only search intensity but also search channels may be affected. McFa- 
dyen and Thomas (1997) survey evidence that long-term unemployed use more formal channels of job search than newly unemployed, who to a larger extent rely on direct contacts to employers, and on their social networks.

van den Berg (1990b) also finds that there is disutility associated with being unemployed compared to employment, ceteris paribus. The observation that people value employment higher than unemployment, ceteris paribus, may be explained with reference to Warr's (1987) vitamin model - about what makes a job important. These factors are 1) secure income, 2) experience of control, 3) a defined goal structure, 4) contacts with other people, and 5) opportunities for skill utilization etc. Another useful reference is the functional model of Jahoda (1981, 1982, 1988), which identifies 5 positive aspects of employment not obtained by leisure. Employment 1) imposes a time structure on the day, 2 ) provides contacts to people outside the family, 3) links individuals to goals and purposes that transcend their own, 4) provides status and identity, and 5) enforces activity. See also Goldsmith, Veum, and Darity, Jr. (1995).

In conclusion, transitions into non-participation may be explained by a discouraged worker type argument: Long term unemployment affects utility, search behaviour, and productivity in a way such that a transition into nonparticipation may become increasingly more likely as unemployment proceeds.

In this study, we build upon these insights in formulating a model in which the event of unemployment results in a loss of utility (relative to being in employed and earning the same income). Moreover, as unemployment lengthens, there will be a gradual loss of search efficiency which will manifest itself as shocks arriving to the job offer arrival rate.

\section{The Model}

\subsection{The Model Setup}

The agents in the model are infinitely lived and risk-neutral. When not employed, they may choose to engage in job search, that is, they may choose to be unemployed - as opposed to being non-participants. Having chosen unemployment, two types of events - job offers and search shocks - can occur at random times. When such an event occurs, unemployed workers must choose between three options: either to continue searching, accept a job offer (if that is the event), or to leave the labour market. Since our focus is on the decision process of unemployed individuals, employment and non-participation are treated as absorbing states in the following. The search model is formulated in continuous time.

Individuals maximise expected discounted utility, all income must be consumed instantaneously, that is, saving and borrowing is not possible. The instantaneous utility flow depends on income and on the labour market state occupied; specifically, there is multiplicative disutility associated with unemployment $^{3}$. Let the instantaneous utility flow be the following function of income

\footnotetext{
${ }^{3}$ We use multiplicative specification because we think a constant share of income describes the mental disutility (subjective costs) better than a constant sum. Several model variations and extensions are discussed in Section 5.
} 
flow, $y$ :

$$
u(y)= \begin{cases}y & \text { if employed (E) } \\ k y & \text { if unemployed (U) } \\ y & \text { if non-participant (N) }\end{cases}
$$

where $0<k<1$ is a constant. These assumption are made in accordance with the empirical evidence above, namely that being unemployed is less valuable than being employed, ceteris paribus. We also make the assumption that unemployment yields lower instantaneous utility than non-participation, ceteris paribus. In any event, the assumption implies that it may eventually become optimal to leave the labour market, see below, so in that sense the assumption is crucial. Unemployed workers receive unemployment benefits $b$, so their instant utility flow is $u^{U}=k b$. The non-participants receive social security benefits ${ }^{4}$, so $u^{N}=b^{N}$.

Two types of events occur while individuals are unemployed: First, job offers arrive, which workers have to immediately decide whether to accept or reject. The arrival of the job offers is governed by a Poisson process $^{5}$ with rate $\lambda$, the evolution of which is specified below. A job offers consists of a random draw from a wage offer distribution $F(w)$. Let $w^{H}$ be the maximum wage available. We assume that

$$
w^{H}>b^{N},
$$

i.e. we assume that there exist jobs which make the individual strictly better off than non-participation. In addition, we assume that it is rational to become a non-participant if the arrival rate of job offers converges to zero, that is, we assume that

$$
b^{N}>k b,
$$

because otherwise one would never observe transitions into non-participation in the model.

The second type of events, denoted search shocks, arrive with Poisson rate $\alpha$. The shocks lead to a drop in the arrival rate of job offers. These changes may stem from declining search activity due to changing search behaviour, as suggested in the previous section, or they may be a result of stigmatisation with respect to elapsed unemployment duration. Upon receipt of a search shock, the job offer arrival rate of an unemployed individual who previously had received $s$ shocks is

$$
\lambda_{s+1}<\lambda_{s}
$$

and

$$
\lim _{s \rightarrow \infty} \lambda_{s}=0 .
$$

The last expression, as (3), ensure that unemployed individuals will eventually leave the labour market. We assume - for tractability - that the shocks do not affect the distribution of the wage offers ${ }^{6}$.

\footnotetext{
${ }^{4}$ The assumption that individuals are free to leave the labour market at any time and receive social assistance is perhaps not realistic. Alternatively, the value $b^{N}$ may be interpreted as the value of home production. We are grateful to Birthe Larsen for pointing this out.

${ }^{5}$ The assumption that arrival of both types of events are described by memoryless Poisson processes is crucial in the current model. Using a process with memory would lead to dynamic effects in (7). This critique applies to a large part of the search literature. We are grateful to Peter Jensen for pointing this out.

${ }^{6} \mathrm{~A}$ variance-preserving downward shift of the wage offer distribution would only strengthen the mechanisms and results which we derive below.
} 
As employment and non-participation are treated as absorbing states, the present values of non-participation and a job with wage $w$ are, respectively,

$$
V^{N}=\frac{b^{N}}{\varrho} \quad \text { and } \quad V^{E}(w)=\frac{w}{\varrho}
$$

where $\varrho$ is the discount factor.

Denoting the present value of unemployment after receipt of $s$ search shocks $V_{s}^{U}$, we can write the asset equation as

$$
\begin{aligned}
\varrho V_{s}^{U}= & k b+\lambda_{s} \underset{w}{\operatorname{Emax}}\left[V^{E}(w)-V_{s}^{U}, 0\right]+ \\
& +\alpha \max \left[V_{s+1}^{U}-V_{s}^{U}, V^{N}-V_{s}^{U}\right] .
\end{aligned}
$$

The first term is the flow income utility, the second is the option value of search, while the third term reflects the option of leaving the labour market and thus avoiding the disutility associated with unemployment (or alternatively, avoiding the search costs). It is clear from the equation that for a fixed $s$, the model is stationary and we may use well-known results for the stationary search model. In particular we know that the optimal strategy is described by reservation wage $w_{s}^{*}$, where the subscript reflects the dependence of the reservation wage on the arrival rate of job offers. The reservation wage after $s$ shocks equates the present value of search and the value of holding a job paying the reservation wage, i.e.

$$
V_{s}^{U}=\frac{w_{s}^{*}}{\varrho} .
$$

If $V_{s+1}^{U}>V^{N}$, that is, if it is not optimal to leave the labour market after receipt of the next shock, the reservation wage may be expressed using (7) and (8) as

$$
\begin{aligned}
w_{s}^{*} & =\frac{\varrho k b+\alpha w_{s+1}^{*}}{\varrho+\alpha}+\frac{\lambda_{s}}{\varrho+\alpha} \int_{w_{s}^{*}}^{w^{H}}\left(w-w_{s}^{*}\right) \mathrm{d} F(w) \\
& =\frac{\varrho k b+\alpha w_{s+1}^{*}}{\varrho+\alpha}+\frac{\lambda_{s}}{\varrho+\alpha} \varphi\left(w_{s}^{*}\right)
\end{aligned}
$$

where $\varphi\left(w_{s}^{*}\right)=\int_{w_{s}^{*}}^{w^{H}}\left(w-w_{s}^{*}\right) \mathrm{d} F(w)$ is the expected gain in the income flow. $\frac{\lambda_{s}}{\varrho+\alpha} \varphi\left(w_{s}^{*}\right)$ thus denotes the option value from continued search. If $V_{s+1}^{U}<V^{N}$, the expected flow income in the next period (the term $\alpha w_{s+1}^{*}$ ) must be replaced by $\alpha b^{N}$.

We need a technical assumption in order to exclude reservation wage bubbles, which are allowed by (9). We assume that, as the arrival rate of job offers approaches zero, non-participation will be the only option considered by the unemployed:

$$
\lim _{s \rightarrow \infty} w_{s}^{*}=\frac{\varrho k b}{\varrho+\alpha}+\frac{\alpha b^{N}}{\varrho+\alpha}<b^{N} .
$$

The inequality follows from (3).

We now have the following proposition:

Proposition 1. The value of unemployment is falling in the number of search shocks:

$$
V_{s}^{U}>V_{s+1}^{U}
$$


and since $w_{s}^{*}=\varrho V_{s}^{U}$,

$$
w_{s}^{*}>w_{s+1}^{*}
$$

Proof. Appendix A.1.

In other words, as the arrival rate of job offers falls, so falls the value of search. This is because the fall in the reservation wage (leading to an increased acceptance probability) cannot offset the influence of the fall in the offer arrival rate.

From the proposition follows directly:

Corollary 1. There exists $\bar{s}$ such that

$$
V_{\bar{s}}^{U} \geq V^{N}>V_{\bar{s}+1}^{U}
$$

Such a value of $\bar{s}$ is called the 'critical number of search shocks', because after the receipt of one additional shock, the $\bar{s}+1^{s t}$, the individual finds that it is no longer optimal to continue searching and leaves the labour market. If the number of shocks can be treated as a proxy for the psychological well-being, the model predicts that the mental health among non-participants is worse than that among the unemployed. This is in contrast with the assumption that the instantaneous utility flow is lower for the unemployed, ceteris paribus.

\subsection{The Reservation Wage and The Critical Number of Search Shocks}

The value of search is directly related to the size of unemployment benefits $b$. The following proposition states some technical results that are used below:

Proposition 2. Given the number of shocks $s$, the reservation wage $w_{s}^{*}$ is increasing and convex in $b$ and $b^{N}$ :

$$
\begin{array}{ll}
\frac{\partial w_{s}^{*}}{\partial b}>0, & \frac{\partial^{2} w_{s}^{*}}{\partial b^{2}}>0, \\
\frac{\partial w_{s}^{*}}{\partial b^{N}}>0, & \frac{\partial^{2} w_{s}^{*}}{\partial\left(b^{N}\right)^{2}}>0
\end{array} \quad \forall s \leq \bar{s} .
$$

Specifically,

$$
\frac{\partial w_{s}^{*}}{\partial b}<1
$$

Proof. Appendix A.2.

Intuitively, search becomes more valuable as unemployment benefits (flow income) increase. The convexity of $w_{s}^{*}$ is related to the increasing reservation wage and the correspondingly falling offer acceptance probability. If $b$ is low, part of an increase in $b$ is offset by a decline in the option value of search. For larger $b$, the option value of search is smaller, and the offsetting value of a decline in option value falls correspondingly, leaving in the limit only the direct impact of $b$ on $w_{s}^{*}$.

In the current model, unemployed workers always have the option of leaving the labour force. The decision to leave depends on the asset values $V_{s}^{U}$ and $V^{N}$, which again depend on unemployment benefits and social assistance. 
Hence, the critical number of shocks, $\bar{s}$, depends on unemployment benefits and social assistance. The next proposition states the relationship between the unemployment benefit and social assistance levels and $\bar{s}$ :

Proposition 3. $\bar{s}$ is non-decreasing in unemployment benefits $b$ and non-increasing in social assistance $b^{N}$.

\section{Proof. Appendix A.3.}

The intuition behind this results is the following: If unemployment benefits are lowered while social assistance benefits remain constant, it leads to a fall in the asset value of search, given $s$. Hence, at what was previously the critical number of shocks, $\bar{s}$, it may no longer be attractive to search, because the flow income is simply too low. Hence, $\bar{s}$ will either remain constant, or it will fall if a sufficiently large decrease in unemployment benefits is introduced. If social assistance is lowered, the situation is the opposite - the outside option becomes less valuable and hence it may be optimal to continue search at values of $s$ larger than $\bar{s}$.

\subsection{Destination Specific Hazard Rates}

Unemployment is left either into employment, when a suitable job offer is received, or into non-participation, when the number of shocks exceeds the critical value.

The transition intensity or destination specific hazard rate (we will use these terms interchangeably) into employment for an individual with $s$ shocks at elapsed unemployment duration $\tau$ may be written as $\vartheta_{s}^{E}=\lambda_{s} \bar{F}\left(w_{s}^{*}\right)$, which is the rate of offer arrival multiplied by the offer acceptance probability. Note that this hazard rate does not depend directly on $\tau$. However, as we show below, the probability that a particular individual has $s$ shocks depends on $\tau$. In general, the destination specific hazard rate into employment may be either increasing or decreasing in the offer arrival rate, and thus in $s$. However, for a large class of distributions, commonly used for describing the wage distribution, including log-normal and Pareto families, the hazard rate is increasing in the offer arrival rate (van den Berg, 1994) ${ }^{7}$. This means that the impact on the hazard rate into employment of an increase in the reservation wage that follows from an increase in the offer arrival rate is more than offset by the direct effect more frequent offers. In the following, we assume that this condition is fulfilled and accordingly $\vartheta_{s}^{E}$ is falling in $s$.

The observed hazard rate into employment at elapsed unemployment duration $\tau$ is an expectation over $s$ for the individual - or shock specific - hazard rates $\vartheta_{s}^{E}$, where the expectation is taken with respect to the distribution of $s$ among those still unemployed at elapsed unemployment duration $\tau$.

Let $U$ denote the event that the individual is unemployed. Denote by $q(s \mid U, \tau)$ the probability that an individual has received $s$ shocks at elapsed unemployment duration $\tau$, given that she is still unemployed. We may write

$$
q(s \mid U, \tau)=\frac{\operatorname{Pr}(s, U \mid \tau)}{\operatorname{Pr}(U \mid \tau)}=\frac{\operatorname{Pr}(U \mid s, \tau) \operatorname{Pr}(s \mid \tau)}{\operatorname{Pr}(U \mid \tau)} .
$$

\footnotetext{
$7_{\text {it }}$ is straightforward to show that the result applies to this model as well.
} 
$\operatorname{Pr}(s \mid \tau)$ is the probability that an individual has received $s$ shocks at $\tau$, this is simply the Poissonian density $p_{p}(s \mid \tau) . \operatorname{Pr}(U \mid \tau)$, the probability that an individual is unemployed at $\tau$ may be expressed as a marginal sum of $\operatorname{Pr}(s, U \mid \tau)$ :

$$
\operatorname{Pr}(U \mid \tau)=\sum_{s=0}^{\bar{s}} \operatorname{Pr}(s, U \mid \tau) .
$$

In the following, denote the survival probability in unemployment with $s$ shocks by $S_{s}(\tau)=\exp \left(-\vartheta_{s} \tau\right){ }^{8}$ The probability of being unemployed at elapsed unemployment duration $\tau$, conditional on the number of shocks received at time $\tau$, may be expressed as an expectation with respect to the joint distribution of 'shock times' of a product of survival probabilities

$$
\operatorname{Pr}(U \mid s, \tau)=\underset{\substack{\tau_{1}, \tau_{2}, \ldots, \tau_{s} \\ 0<\tau_{1}, \ldots, \tau_{s}}}{\mathrm{E}}\left[S_{0}\left(\tau_{1}\right) S_{1}\left(\tau_{2}\right) \ldots S_{s-1}\left(\tau_{s}\right) S_{s}\left(\tau_{s+1}\right)\right]
$$

where $\tau_{i}, i=1,2, \ldots, s$ denote times between shocks (survival times in unemployment with $i-1$ shocks), and $\tau_{s+1} \equiv \tau-\tau_{1}-\tau_{2}-\ldots-\tau_{s}$ is the time since the $s$ 'th shock.

The observed transition intensity at elapsed time $\tau$ is simply a weighted average over $s$ of $\vartheta_{s}^{E}$ :

$$
\vartheta^{E}(\tau)=\sum_{s=0}^{\bar{s}} \vartheta_{s}^{E} q(s \mid U, \tau) .
$$

It is intuitively obvious that, as $\tau$ increases, the mass of the Poissonian distribution shifts toward larger number of shocks. At the same time, those with few shocks tend to leave unemployment faster (due to their larger transition rate into employment), leading to a further rightward shift of the distribution of $s$ as $\tau$ increases. Hence, we have the result that the transition intensity into employment decreases with $\tau$, because $\vartheta_{s}^{E}$ decreases in $s$. Formally, we have

Proposition 4. The transition intensity into employment is decreasing in time:

$$
\frac{\partial}{\partial \tau} \vartheta^{E}(\tau)<0
$$

Transitions into non-participation occur when unemployed workers receive their $\bar{s}+1^{\text {st }}$ shock. In a short time interval, this is possible only if the unemployed worker already has $\bar{s}$ shocks, and in that case the transition intensity is $\alpha$. In an observed sample of unemployed individuals (where $s$ is not observed) the transition rate into non-participation becomes (from (14))

$$
\vartheta^{N}(\tau)=\alpha \frac{\operatorname{Pr}(\bar{s}, U \mid \tau)}{\operatorname{Pr}(U \mid \tau)}
$$

When elapsed time increases, unemployed workers receive more and more shocks. Part of them will leave the labour force, and among those still participating, the share of individuals with large $s$ increases, due to the properties of the Poissonian distribution. This leads to an increase of $\vartheta^{N}(\tau)$ with elapsed unemployment duration. This is stated in the following proposition:

Proposition 5. The transition intensity into non-participation is increasing in elapsed time: $\frac{\partial}{\partial t} \vartheta^{N}(\tau)>0$.

\footnotetext{
${ }^{8}$ Note that $\tau$ here denotes the duration since the $s^{\prime}$ th shock was received, and not unemployment duration.
} 


\section{Changing Economic Incentives to Search}

In this section we analyse the effects of conducting incentive based labour market policies on the transition intensities and participation rates. We are interested only in comparative statics, so we do not consider any issues that are related to anticipation of the reforms. That is, we are not interested in paths of adjustment to anticipated reforms. Moreover, we ignore general equilibrium considerations of such reforms and focus solely on the impact changing incentives have on individuals, ceteris paribus, that is, in a world where the labour market equilibrium is unaffected by such changing incentives. A natural next step would be to embed our model into an equilibrium framework such as that analysed by Fredriksson and Holmlund (2001), but such an analysis is beyond the scope of the present paper. We present the results for three types of policy reforms, namely:

- a decrease in unemployment benefits, $b$, while keeping social assistance, $b^{N}$, constant;

- a decrease in social assistance, $b^{N}$, while keeping UI benefits, $b$, constant; and

- a simultaneous decrease in both $b$ and $b^{N}$.

\subsection{Decreasing Unemployment Benefits only}

Decreasing the level of unemployment benefits affect the value of search and thus the reservation wage, $w_{s}^{*}$, directly. Moreover, lowering unemployment benefits affect the relative value of search compared to non-participation and thus potentially the critical number of shocks $\bar{s}$. Thus, both the transition rate into employment and the transition rate into non-participation are affected by changing unemployment benefits.

Let unemployment benefits fall without anticipation from $b_{1}$ to $b_{2}$. The change in $b$ affects the transition intensity into employment through $w_{s}^{*}$ (acceptance effect) and through $\bar{s}$ (composition effect). The transition rate into nonparticipation is affected only through a composition effect. By proposition 3, $\bar{s}_{1} \geq \bar{s}_{2}$. The associated change in the corresponding transition intensities to employment may now be written as

$$
\begin{aligned}
\vartheta^{E}\left(\tau ; b_{1}\right)-\vartheta^{E}\left(\tau ; b_{2}\right) & =\sum_{s=0}^{\bar{s}_{1}} \vartheta_{s}^{E}\left(b_{1}\right) q\left(s \mid U, \tau ; b_{1}\right)-\sum_{s=0}^{\bar{s}_{2}} \vartheta_{s}^{E}\left(b_{2}\right) q\left(s \mid U, \tau ; b_{2}\right) \\
& =\sum_{s=0}^{\bar{s}_{2}}\left[\vartheta_{s}^{E}\left(b_{1}\right) q\left(s \mid U, \tau ; b_{1}\right)-\vartheta_{s}^{E}\left(b_{2}\right) q\left(s \mid U, \tau ; b_{2}\right)\right]+ \\
& +\sum_{s=\bar{s}_{2}+1}^{\bar{s}_{1}} \vartheta_{s}^{E}\left(b_{1}\right) q\left(s \mid U, \tau ; b_{1}\right)
\end{aligned}
$$

If the change in $b$ is sufficiently small, then $\bar{s}_{1}=\bar{s}_{2}$ (the second sum in the equation above disappears) and $q\left(s \mid U, \tau ; b_{1}\right)=q\left(s \mid U, \tau ; b_{2}\right)$. Using the fact that the fall in $b$ leads to an increase in $\vartheta^{E}$ (through the acceptance effect) we can conclude that the difference is negative. Hence a small decrease in unemployment benefits leads to a higher observed transition intensity into employment, 
but does not affect the transition rate into non-participation. The increase is caused by a decrease in the value of search (and hence in the reservation wage) while the value of employment is unaffected.

If the change in $b$ is large enough, then according to the proposition 3, $\bar{s}_{2}<\bar{s}_{1}$, which means that workers will find it optimal to leave the labour market at a lower number of shocks (that is, earlier in the unemployment spell) than before the decrease in unemployment benefits. For the first term we have, as before, $\vartheta_{s}^{E}\left(b_{1}\right)<\vartheta_{s}^{E}\left(b_{2}\right)$ and now $q\left(s \mid U, \tau ; b_{1}\right)<q\left(s \mid U, \tau ; b_{2}\right)$ (this can be seen from (14)), reinforcing this effect. Note that since the probability mass still must sum to one, and since larger probability is now put on higher hazard rates, the second sum in the equation above never dominates. As before, lower unemployment benefits lead to a lower reservation wage and concludingly to a higher transition intensity into employment, given $s$ - the number of shocks recived. This effect is captured by the increase in $\vartheta_{s}^{E}(b)$. Moreover, workers with large numbers of shocks (and thus a low offer arrival rate) are now exiting the labour market at an earlier stage. In this way the share of those with a low number of shocks increases and hence the observed average transition intensity increases too. This effect is captured partly by the fact that $q\left(s \mid U, \tau ; b_{1}\right)<$ $q\left(s \mid U, \tau ; b_{2}\right)$, and partly by the decrease in the critical number of shocks, $\bar{s}$. This is a type of selection or composition effect. Relatively weak unemployed workers, who would previously have left the labour market later, will now leave earlier, leading in this way to higher average offer arrival rates among those who still stay in unemployment. This is an effect of falling value of unemployment. Thus, the transition rate into employment unambiguously increases.

The transition intensity to non-participation is related to the share of the individuals who have received the critical number of shocks, $\bar{s}$, in the total pool of unemployment. Intuitively, it is clear that if $\bar{s}$ increases, the unemployed individuals will be "spread" across a wider range of shocks and hence there is relatively less of them with $\bar{s}$ shocks. However, if the shock specific hazard rate falls "too much", at the new $\bar{s}$, a larger than before share of unemployed workers may have $\bar{s}$ shocks and hence the transition intensity into non-participation may actually increase. We have following proposition:

Proposition 6. The transition intensity into non-participation is decreasing in $\bar{s}$, given that

$$
\vartheta_{s-1}^{E}-\vartheta_{s}^{E}>\vartheta_{s}^{E}-\vartheta_{s+1}^{E} \quad \forall s \geq 1
$$

Proof. Formal proof is given in the appendix A.4.

The intuition behind the condition (21) is that a single shock must not lower the $\vartheta_{s}^{E}$ too much. Otherwise, it results into a large share of unemployed individuals with very low job chances and a large number of shocks, and hence a larger than before $\vartheta^{N}(\tau)$. We assume below that (21) is satisfied.

Thus, if the lowering of unemployment benefits is sufficiently large, such that $\bar{s}_{2}<\bar{s}_{1}$, the transition rate into non-participation increases, too. Unemployment duration therefore surely falls as unemployment benefits are lowered, but this is not necessarily a desirable outcome. Namely, depending on the size and timing of the increase of transition intensities, the participation rate may either increase or fall. An increase is the case if the faster transitions to employment causes the number of workers, who stay in unemployment until they receive $\bar{s}$ shocks, to 
fall. Otherwise, the increased number of workers, just at $\bar{s}$ leads to an increase in the flow into non-participation and hence a decrease in the participation rate.

As a result of the reform, unemployment unambiguously falls. Whether the outcome of the reform is desirable depends on the underlying parameters and the social welfare function.

\subsection{Decreasing Social Assistance only}

Suppose instead that we conduct a policy which makes non-participation less attractive; a lowering of social assistance benefits, $b^{N}$, from $b_{1}^{N}$ to $b_{2}^{N}$. Note first that if the decline in social assistance is sufficiently small such that $\bar{s}$ is unaffected, the transition rate from unemployment to non-participation is unaffected. The transition rate into employment increases marginally, namely, the reservation wage for individuals who have received $\bar{s}$ shocks will fall, leading to an increase in the hazard rate for those individuals. According to (9), this will affect the hazard rate into employment also at lower number of shocks, too, because of anticipation effects, but this effect is of an indirect nature, and may thus be quite small.

If the change in $b^{N}$ is sufficiently large, the critical number of shocks will increase, say, from $\bar{s}_{1}$ to $\bar{s}_{2}>\bar{s}_{1}$. By proposition 6 , this leads to a lower transition rate into non-participation. As this will induce people to search longer, the average unemployed worker will now have received more search shocks, leading to a lower transition rate into employment, ceteris paribus. This is, however, only a composition effect, arising from the fact that those deciding to stay longer in the labour market as a result of the change in social assistance have a low hazard rates into employment. The individual specific hazard rate, given the number of shocks, $\vartheta_{s}^{E}$ increases unambiguously because the shock-specific reservation wage falls.

Formally,

$$
\begin{aligned}
\vartheta^{E}\left(\tau ; b_{1}^{N}\right)-\vartheta^{E}\left(\tau ; b_{2}^{N}\right)= & \sum_{s=0}^{\bar{s}_{1}} \vartheta_{s}^{E}\left(b_{1}^{N}\right) q\left(s \mid U, \tau ; b_{1}^{N}\right)-\sum_{s=0}^{\bar{s}_{2}} \vartheta_{s}^{E}\left(b_{2}^{N}\right) q\left(s \mid U, \tau ; b_{2}^{N}\right) \\
= & \sum_{s=0}^{\bar{s}_{1}}\left[\vartheta_{s}^{E}\left(b_{1}^{N}\right) q\left(s \mid U, \tau ; b_{1}^{N}\right)-\vartheta_{s}^{E}\left(b_{2}^{N}\right) q\left(s \mid U, \tau ; b_{2}^{N}\right)\right] \\
& -\sum_{s=\bar{s}_{1}+1}^{\bar{s}_{2}} \vartheta_{s}^{E}\left(b_{2}^{N}\right) q\left(s \mid U, \tau ; b_{2}^{N}\right)
\end{aligned}
$$

The hazard rates in the first sum increase; $\vartheta_{s}^{E}\left(b_{2}^{N}\right)>\vartheta_{s}^{E}\left(b_{1}^{N}\right)$, while the probabilities associated with them decline; $q\left(s \mid U, \tau ; b_{2}^{N}\right)<q\left(s \mid U, \tau ; b_{1}^{N}\right)$. The second sum is clearly negative. Overall, the effect on the transition rate into employment is ambiguous.

However, we expect the composition effect to dominate at long unemployment duration where the share of individuals with a large number of shocks is high. At short durations, the income effect should dominate. Hence we expect the $\vartheta_{E}(\tau)$ to increase for short durations and fall for long durations. The participation rate will unambiguously increase because the reservation wages fall and the transitions to non-participation occur later. The effect on unemployment duration and the unemployment rate, however, is ambiguous. 


\subsection{A Simultaneous Cut in Unemployment Benefits and Social Assistance}

It would thus seem that a simultaneous cut in unemployment benefits and social assistance should be able to achieve the combined goal of reducing the unemployment rate without increasing non-participation. Lowering unemploymentbenefits increases both hazard rates out of unemployment, but an appropriately dosed simultaneous cut in social assistance would keep the optimal number of shocks constant, thus not affecting the exit rate from the labour market, and simultaneously reinforcing the effect on the job finding rate because of the reservation wage effect of social assistance cuts. However, the exact dosages of the two types of cuts will be an empirical question. For this reason, we now turn to a simulation exercise, where a search model of the type specified above is calibrated to fit Danish unemployment to employment hazard rates and the aggregate unemployment rate.

\subsection{A Calibration Exercise}

We will formulate a very simple flow equilibrium model of the labour market embedding the partial search model specified above. The model allows for transitions between unemployment and employment, and between unemployment and non-participation (flows between employment and non-participation consist mainly of labour market entry and retirement, as well as maternity leave periods etc. These are assumed in the model to cancel out, thus they are not included). Let the transition rate from employment to unemployment be $\delta$ (assumed constant over employment duration), and let the transition rate from non-participation to unemployment be $\gamma$. We then have a flow equilibrium condition; flows into and out of employment and non-participation should be identical;

$$
\begin{aligned}
\delta E & =\bar{\vartheta}^{E} U \\
\gamma N & =\bar{\vartheta}^{N} U
\end{aligned}
$$

where

$$
\begin{aligned}
\bar{\vartheta}^{E} & =\int_{0}^{\infty} \vartheta^{E}(\tau) f^{U}(\tau) \mathrm{d} \tau \\
\bar{\vartheta}^{N} & =\int_{0}^{\infty} \vartheta^{N}(\tau) f^{U}(\tau) \mathrm{d} \tau
\end{aligned}
$$

are the corresponding mean transition intensities and

$$
f^{U}(\tau)=\left[\vartheta^{E}(\tau)+\vartheta^{N}(\tau)\right] \exp \left\{-\int_{0}^{\tau}\left(\vartheta^{E}(t)+\vartheta^{N}(t)\right) \mathrm{d} t\right\}
$$

is the probability density function of spell lengths. From (23) it follows immediately that the steady-state employment, unemployment, and non-participation 
rates are

$$
\begin{aligned}
e & =\frac{\gamma \bar{\vartheta}^{E}}{\delta \bar{\vartheta}^{N}+\gamma \bar{\vartheta}^{E}+\gamma \delta} \\
u & =\frac{\gamma \delta}{\delta \bar{\vartheta}^{N}+\gamma \bar{\vartheta}^{E}+\gamma \delta} \\
n & =\frac{\delta \bar{\vartheta}^{N}}{\delta \bar{\vartheta}^{N}+\gamma \bar{\vartheta}^{E}+\gamma \delta}
\end{aligned}
$$

Given a set of model parameters, these quantities may all be calculated quite easily.

We analyse the three policy reforms as described above. The parameters were choosen according to the Danish labour market indicators: $b^{N}=7000$ (DKK monthly) and $b=12000$, these numbers correspond to the actual Danish benefit levels; the values for $k=0.35$ and $\lambda_{0}=0.35$ were calibrated in order to get a roughly correct value for unemployment-to-employment hazard rate for short unemployment spells; $\gamma=0.01$ and $\delta=0.01$ were calibrated according to the employment and unemployment rate in the main working-age population (age group 30-54). The shock-specific arrival rates were specified as $\lambda_{s+1}=$ $d \lambda_{s}$ where $d=0.5 ; d$ and $\alpha=0.2$ were calibrated according to the actual duration dependence of the hazard rate. A high value for the discount rate is needed $(\varrho=0.05)$ because the model assumes the jobs last forever. The wage offer distribution was assumed to be lognormal with mean 15700 and standard deviation 5700 DKK. In this way roughly correct moments of the wage distribution were achieved. The technical details of simulation are described in the appendix B.1.

Let us start with the wage offer distribution. In a stationary search model without on-the-job search, the observed wage distribution is simply the truncated wage offer distribution. However, in the case with a decling hazard rate, this relation is no longer simple, as the individuals have different reservation wages. It is instructive to look at the distribution of accepted wages after a certain unemployment duration. Figure 1 presents such a distributions for three different unemployment durations: $\tau=1$ month, $\tau=6$ months and $\tau=12$ months for the original model parameters. Most of the short term unemployed with $\tau=1$ month elapsed duration have received no shocks. Their reservation wage $w_{0}^{*}$ is slightly below 14000 DKK monthly. However, in addition to the truncated log-normal wage distribution we observe a small mass at lower wages. This corresponds to individuals who have already received at least one shock. As the duration increases, the share of those individuals increases and we observe more and more mass below $w_{0}^{*}$. More and more unemployed have received $\bar{s}$ (= 4 according to current parameters) shocks and the distribution converges to a log-normal, truncated from below at $w_{\bar{s}}^{*}$.

The other characteristics of the labour market for the original model are as follows (Table 1): the average length of unemployment spells $\bar{T}=6.2$ months, the average monthly hazard rates into employment and non-participation $\bar{\vartheta}^{E}=$ 0.132 and $\bar{\vartheta}^{N}=0.019$ respectively, the employment rate $e=0.820$, unemploymentto-population rate $u=0.062$, non-participation rate $n=0.118$ and the unemploymentto-labour force rate $u$ rate $=0.070$.

We consider first a policy reform where the unemployment benefit level is lowered to $9000 \mathrm{DKK}$, thereafter a reform where social assistance is decreased 


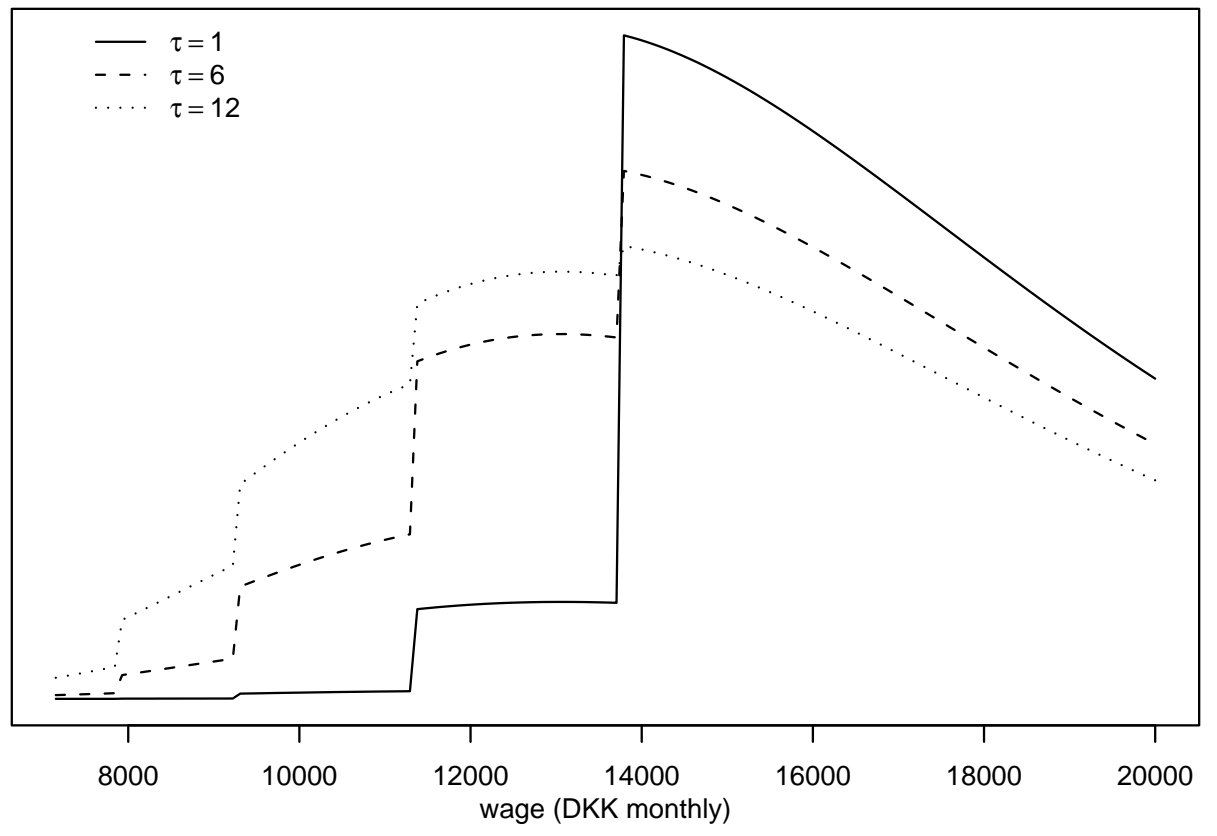

Figure 1: The accepted wage distribution depending on the length (in months) of the unemployment spell.

\begin{tabular}{lrrrr}
\hline \hline & original & $\mathrm{R} 1$ & $\mathrm{R} 2$ & $\mathrm{R} 3$ \\
\hline$b$ & 12000 & 9000 & 12000 & 9000 \\
$b^{N}$ & 7000 & 7000 & 5000 & 5000 \\
$\bar{s}$ & 4 & 3 & 6 & 5 \\
$\bar{T}$ & 6.196 & 5.619 & 5.934 & 6.015 \\
$\bar{\vartheta} E$ & 0.132 & 0.146 & 0.129 & 0.137 \\
$\bar{\vartheta}^{N}$ & 0.019 & 0.028 & 0.007 & 0.012 \\
$e$ & 0.820 & 0.794 & 0.882 & 0.863 \\
$u$ & 0.062 & 0.054 & 0.069 & 0.063 \\
$n$ & 0.118 & 0.152 & 0.049 & 0.074 \\
$u$ rate & 0.070 & 0.064 & 0.072 & 0.068 \\
\hline \hline
\end{tabular}

Table 1: The effect of the policy reforms. Explanation in text.

to 5000 DKK, and at last a combined reform where both of the transfers are lowered. The main indicators for corresponding equilibria are presented in Table 1 as well.

The reform R1 (lowering unemployment benefits only from 12000 to 9000 DKK monthly) clearly leads to a fall in the mean length of unemployment spells, $\bar{T}^{U}$, and a fall in the unemployment rate by 0.6 percentage point. However, the decrease is mainly driven by workers increasingly leaving the labour market. This fact is reflected by a significant increase in $\bar{\vartheta}^{N}$, an increase in nonparticipation $n$ from 0.118 to 0.152 , and a fall in the employment-to-population rate $e$ from 0.820 to 0.794 . Figure 2 reveals that although both types of hazard rates are increasing, the increase in $\vartheta^{N}$ is significantly larger. 


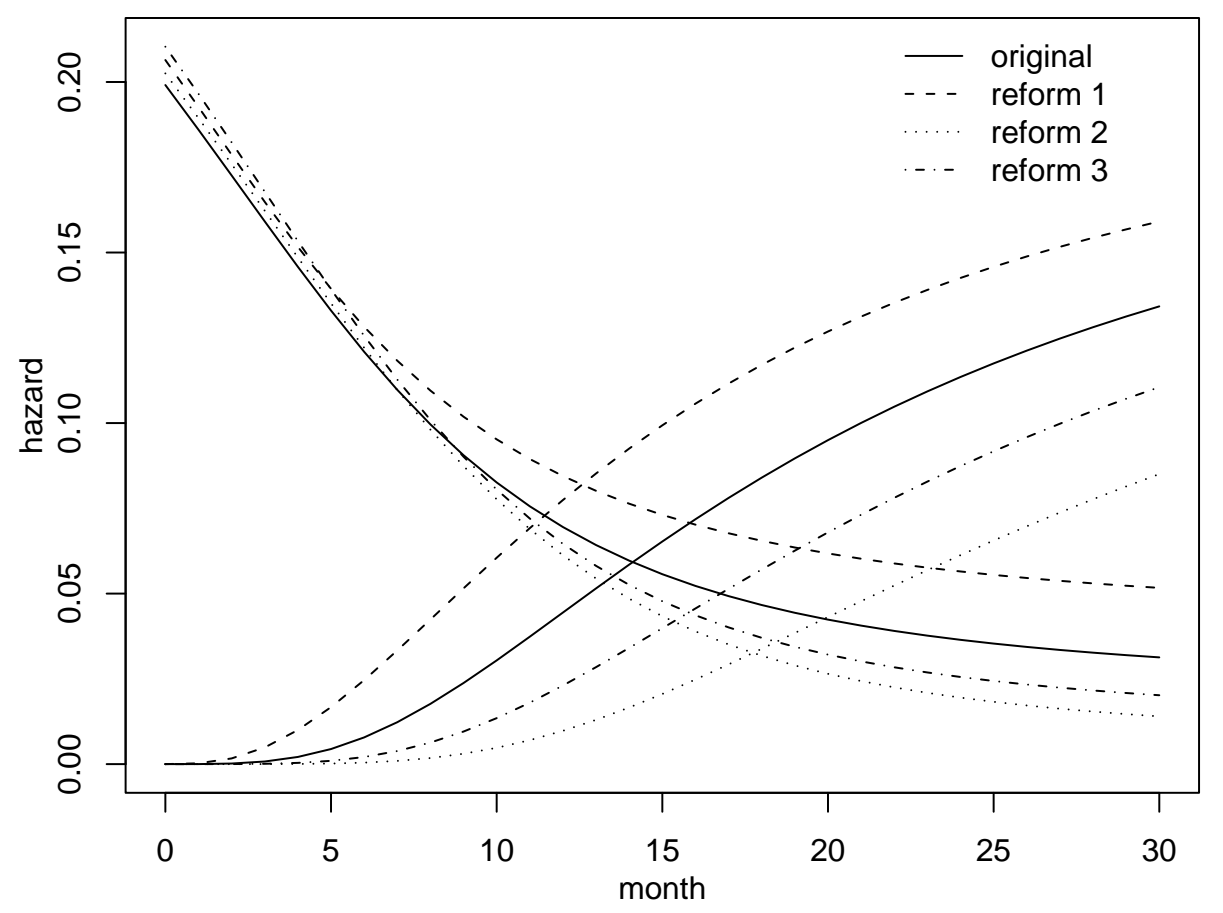

Figure 2: The effect of the policy reform on the hazard rates as a function of duration. $\vartheta^{E}(\tau)$ (falling) and $\vartheta^{N}(\tau)$ (increasing) before the reform (solid line), and after the corresponding reforms.

The reform R2 (lowering social assistance from 7000 to 5000 DKK monthly) leads to an increase in employment and participation rates, while the unemployment rate remains virtually unchanged (it increases by 0.2 percentage point). The mean unemployment duration falls slightly although the unemployment rate increases, this is because of the the increase in $\vartheta^{E}(\tau)$ at low unemployment durations. However, at the end of the first year of unemployment, the hazard rate into employment in fact falls below the same hazard rate for the reference case (dotted line on the Figure 2). This is because at long unemployment duration the composition effect, arising here from the fact that workers with very low offer arrival rates stay longer in unemployment as the transition intensity into non-participation has declined, dominates the income effect, as described in section 4.2 .

Indicators for the reform R3 are between those of R1 and R2. Note that all the indicators are favorable in this case, although the effects are small. The mean unemployment duration decreases very little, the average hazard rate into employment is virtually unchanged while that into non-participation decreases. The main effect of the reform is the fact that non-participation decreases and employment increases by almoust the same amount, leaving the unemployment rate virtually unaffected. R3 can be regarded as continuation of R1 by using an extra policy instrument, $b^{N}$. This instrument can be used against the undesired fact that people after R1 increasingly tend to leave the labour force. In this way a higher transition rate into employment can be achieved on individual level. However, hindering the exits to non-participation may lower the average 
transition rate out from unemployment and hence the aggregate unemployment may still increase due to increased participation.

According to the common indicators, the first reform is the most successful one with unemployment decreasing 0.6 percentage points and average unemployment duration decreasing by more than half a month. However, from the participation rate perspective, one should rather prefer the second reform, although it leads to a lower average hazard rate into employment for much of the unemployment spell. The third refrm leads both to shorter unemployment spells and higher participation rate as predicted by the model. However, all the effects are small. Lower benefits encourage unemployed workers to take jobs faster, but due to the lower value of unemployment, the incentives to stay in the labour force are not as large as for the second reform.

In order to assess the sensitivity of the results with respect to the parameters, a number of additional simulations were run. A summary of these is given in the appendix B.2. Although the results vary, the main message remains robust: Lower unemployment benefits decrease the unemployment rate but this is not the most efficient way in order to boost participation. In order to increase participation, one has to make non-participation less attractive.

\section{$5 \quad$ Alternative Specifications}

In this section we investigate briefly the implications of changing two of the crucial assumption of the model. First, we look at additive search costs instead of the multiplicative factor we used in the reference model. This will probably be considered a more conventional specification than the reference model. Next, we look at shocks to the utility function - interpreted as declining well-being - rather than to offer arrival rates. This is perhaps less conventional than the reference model.

\subsection{Additive Search Costs}

Suppose that unemployment is not related with multiplicative fall in welfare (as in equation 1 ) but with an additive one:

$$
u(y)= \begin{cases}y & \text { if employed } \\ y-c & \text { if unemployed } \\ y & \text { if non-participant. }\end{cases}
$$

This setup is common when $c$ is perceived as reflecting search costs. The asset equation (7) now looks like:

$$
\begin{aligned}
\varrho V_{s}^{U}= & k-c+\lambda_{s} \underset{w}{\operatorname{m}} \max \left[V^{E}(w)-V_{s}^{U}, 0\right]+ \\
& +\alpha \max \left[V_{s+1}^{U}-V_{s}^{U}, V^{N}-V_{s}^{U}\right] .
\end{aligned}
$$

Most of the results from the model presentation above carry over to the new case. The proofs are analogous. Namely:

- Shocks lead to a fall in the value of unemployment $V_{s}^{U}>V_{s+1}^{U}$ (proposition 1). Hence there exists a critical number of shocks $\bar{s}$ as before. Hence, 
the transition intensity into employment is decreasing and that into inactivity is increasing in time as before.

- Increases in unemployment benefits and social assistance both lead to increases in the reservation wage: $\frac{\partial}{\partial b} w_{s}^{*}>0$ and $\frac{\partial}{\partial b^{N}} w_{s}^{*}>0$.

- A fall in $b$ leads to a decrease (or at least not an increase) and a fall in $b^{N}$ leads an increase (or at least not a decrease) in $\bar{s}$.

\subsection{Shocks to the Utility Function}

Suppose that being unemployed lowers general well-being or utility for reasons explained in section 2. In our model, we would capture this by allowing shocks to hit the utility function rather than the job offer arrival rate. Hence, we have the following specificiation:

$$
u(y)= \begin{cases}y & \text { if employed } \\ k_{s} y & \text { if unemployed } \\ y & \text { if non-participant }\end{cases}
$$

where $k_{s}>k_{s+1}$, for all $k$.

In this case, the Bellman equation writes as

$$
\begin{aligned}
\varrho V_{s}^{U}= & k_{s} b+\lambda \underset{w}{\operatorname{Emax}}\left[V^{E}(w)-V_{s}^{U}, 0\right]+ \\
& +\alpha \max \left[V_{s+1}^{U}-V_{s}^{U}, V^{N}-V_{s}^{U}\right] .
\end{aligned}
$$

and it is straightforward to show that, given $s$, a reservation wage strategy is optimal. Moreover, since

$$
\frac{\partial w_{s}^{*}}{\partial b}>0
$$

it follows that the value function and the reservation wage are decreasing functions of $s$. This result is intuitively obvious; as the utility in unemployment declines, individuals find it optimal to accept lower and lower wages.

Moreover, under the assumption that non-participation is prefered to infinite unemployment $\left(\lambda \varphi\left(w_{\infty}^{*}\right)<\alpha b^{N}\right)$, it can easily be shown, by applying the same proof as in our main example, that there exists a critical value $\bar{s}$, such that the $\bar{s}+1^{\text {st }}$ shock induces the individual to leave the labour market.

Having established these properties, we immediately have that $\vartheta_{s}^{E}<\vartheta_{s+1}^{E}$, since the reservation wage is falling in $s$, and the offer arrival rate does not change in this model. Hence, it is straightforward to show that

$$
\frac{\partial}{\partial \tau} \vartheta^{E}(\tau)>0
$$

and, for reasons similar to those specified in our leading example,

$$
\frac{\partial}{\partial \tau} \vartheta^{N}(\tau)>0
$$

Hence, in this specification, both the hazard rate into employment and the hazard rate out of the labour force exhibit positive duration dependence. 
Finally, the effects of various types of benefit cuts carry over from the main case, with the exception that a cut in unemployment benefits now may increase or decrease the hazard rate into employment, since the selection effect - stemming from the decline in $\bar{s}-$ now leads to labour market exit of individuals with relatively high hazard rates into employment. Similarly, a decline in both unemployment benefits and social assistance, or alternatively a decline in social assistance alone, leads to an increase in $\bar{s}$, hence unanimously increasing the hazard rate into employment in both cases.

\section{Discussion and Conclusion}

We have presented a search model in which individuals are hit by search shocks. That is, now and then the search environment is disrupted by stigma effects or by changes in search behaviour, which leads to lower job offer arrival rates. We have also introduced into this framework an option for leaving the labour market altogether and thus avoiding the disutility/search associated with being unemployed.

We show that this model leads to observed hazard rates into employment and non-participation the shapes of which are observed in real data, namely, a hazard rate into employment which exhibits negative duration dependence and a hazard rate into non-participation exhibiting positive duration dependence. The latter phenomenon shows that discouragement may be an important factor in explaining exits from the labour market.

Having established some properties of the model, we investigate the effects of changes in economic incentives in such a model. When changing the incomes of those out of work, it is important to consider not only how their transition rates into employment are affected, but also how their transition rates out of the labour force are affected, in order to avoid undesirable outcomes. This is demonstrated theoretically as well as in a calibration exercise, where the search model we have developed is embedded into a (admittedly) very simple flow equilibrium model of the labour market. The calibration exercise also suggests that appropriately dosed changes in the two benefit levels may achieve the dual goal: faster transitions to employment on individual level and increasing the labour force.

\section{A Proofs of the propositions}

\section{A.1 Proof of proposition 1}

We use the reservation wage instead of value function, according to (8) the proofs are identical.

Let $w_{s}^{*}>u^{N}$. Assume by contradiction that $w_{s+1}^{*} \geq w_{s}^{*}>u^{N}$. Using equation (9) we can write:

$$
w_{s}^{*}=\frac{\varrho k b+\alpha w_{s+1}^{*}}{\varrho+\alpha}+\frac{\lambda_{s}}{\varrho+\alpha} \varphi\left(w_{s}^{*}\right) \leq w_{s+1}^{*} .
$$

Isolating $w_{s+1}^{*}$ yields

$$
w_{s+1}^{*} \geq k b+\frac{\lambda_{s}}{\varrho} \varphi\left(w_{s}^{*}\right)>k b+\frac{\lambda_{s+1}}{\varrho} \varphi\left(w_{s+1}^{*}\right)
$$


where the second inequality follows from the facts that $\lambda_{s+1}<\lambda_{s}$ and $w_{s+1}^{*} \geq$ $w_{s}^{*}$. Using (7) for expressing $w_{s+1}^{*}$ yields

$$
w_{s+1}^{*}=k b+\frac{\lambda_{s+1}}{\varrho} \varphi\left(w_{s+1}^{*}\right)+\frac{\alpha}{\varrho}\left(w_{s+2}^{*}-w_{s+1}^{*}\right) .
$$

Comparing the last two results we can conclude that $w_{s+2}>w_{s+1}$. Hence, if the reservation wage increases at a particular $s$, it will be strictly increasing thereafter. Intuitively, this means that increasing future wage expectations are balancing the falling arrival rate. This is exactly what the assumption about reservation wage bubbles (11) excludes. Hence, $w_{s+1}^{*}<w_{s}^{*}$.

\section{A.2 Proof of proposition 2}

From (9) we have:

$$
\frac{\partial w_{s}^{*}}{\partial b}=\frac{\varrho k+\alpha \frac{\partial}{\partial b} w_{s+1}^{*}}{\varrho+\alpha}+\frac{\lambda_{s}}{\varrho+\alpha} \frac{\partial}{\partial b} \varphi\left(w_{s}^{*}\right)=\frac{\varrho k+\alpha \frac{\partial}{\partial b} w_{s+1}^{*}}{\varrho+\alpha}-\frac{\vartheta_{s}^{E}}{\varrho+\alpha} \frac{\partial w_{s}^{*}}{\partial b},
$$

where $\vartheta_{s}^{E}=\lambda_{s} \bar{F}\left(w_{s}^{*}\right)$ is the intensity of transitions into employment after $s$ shocks. Isolating $\frac{\partial}{\partial b} w_{s}^{*}$ yields:

$$
\frac{\partial w_{s}^{*}}{\partial b}=\frac{\varrho k+\alpha \frac{\partial}{\partial b} w_{s+1}^{*}}{\varrho+\alpha+\vartheta_{s}^{E}}
$$

For the next-to-last shock, the term $\frac{\partial w_{s+1}^{*}}{\partial b}$ vanishes because $b^{N}$ does not depend on $b$ and we have:

$$
\frac{\partial w_{\bar{s}}^{*}}{\partial b}=\frac{\varrho k}{\varrho+\alpha+\vartheta \frac{E}{\bar{s}}}
$$

which is positive but less than 1 . Using these facts and equation (35), we can get the same results for every $s$ by induction.

The second derivative (from equation 9 ) is:

$$
\frac{\partial^{2}}{\partial b^{2}} w_{s}^{*}=\frac{\alpha \frac{\partial^{2}}{\partial b^{2}} w_{s+1}^{*}}{\varrho+\alpha}+\frac{\lambda_{s}}{\varrho+\alpha} \frac{\partial^{2}}{\partial b^{2}} \varphi\left(w_{s}^{*}\right)=\frac{\alpha \frac{\partial^{2}}{\partial b^{2}} w_{s+1}^{*}}{\varrho+\alpha}+\frac{\lambda_{s}}{\varrho+\alpha} f\left(w_{s}^{*}\right) \frac{\partial}{\partial b} w_{s}^{*} .
$$

For the next-to-last shock it yields

$$
\frac{\partial^{2}}{\partial b^{2}} w_{\bar{s}}^{*}=\frac{\lambda_{s}}{\varrho+\alpha} f\left(w_{\bar{s}}^{*}\right) \frac{\partial}{\partial b} w_{\bar{s}}^{*}>0
$$

if $f\left(w_{\bar{s}}\right)>0$ and because $\frac{\partial}{\partial b} w_{\bar{s}}^{*}>0$. Hence, $w_{s}^{*}$ is a convex function of $b$ if $f\left(w_{\bar{s}}\right)>0$. Note, in particular, that $w_{s}^{*}$ is a linear function if $f\left(w_{\bar{s}}\right)>w^{H}$.

The proof for $b^{N}$ is analogous.

\section{A.3 Proof of proposition 3}

From corollary 1 we have directly:

$$
w_{\bar{s}}^{*} \geq u^{N}>w_{\bar{s}+1}^{*} .
$$

Consider now Figure 3. The reservation wages $w_{s}^{*}, w_{s+1}^{*}$ and $w_{s+2}^{*}$ are depicted as functions of benefits $b$. The functions are increasing and convex in $b$ and 


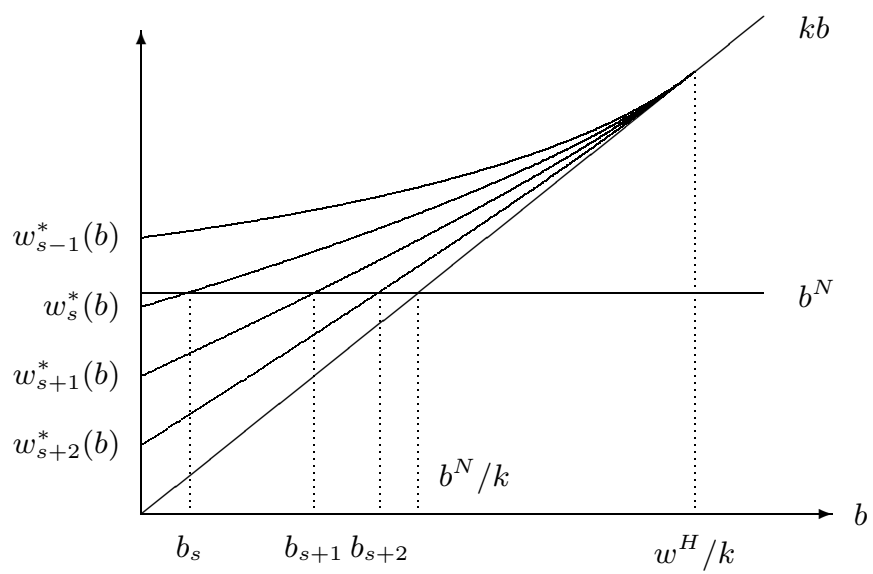

Figure 3: $w_{s}^{*}$ and $u^{N}$ as functions of $b$

decreasing in $s$ if $b<w^{H} / k$ (see proposition 2). If $b \geq w^{H} / k$, none of the wage offers are acceptable and the value of unemployment consist of the flow value only, $w_{s}(b)=k b$ which does not depend on $s$. As the value of being out of the labour force do not depend on $b$, it may be depicted as a horizontal line.

It is clear from the Figure that as long as the level of benefits $b$ satisfies $b_{s} \leq b<b_{s+1}$, it is optimal to leave the labour force after $s$ shocks, i.e. $\bar{s}=s$. If the benefits will be increased so that $b_{s+1} \leq b<b_{s+2}, \bar{s}=s+1$. If $b \geq b^{N} / k$, then it is never optimal to leave the labour force.

Decreasing $b$ leads to earlier leaving of the labour force. However, even if $b$ is 0 , it may still be optimal to search if the arrival rate of job offers is high enough. This is depicted as the curve $w_{s-1}^{*}(b)$ which never falls below $b^{N}$. Hence $\bar{s}$ will never fall below $s-1$.

The effect of social assistance on the search behaviour is depicted in the Figure 4 . Given $s$ and $b$, the reservation wage is an increasing convex function of $b^{N}$ (by proposition 2). If the arrival rate converges to zero, the reservation wage converges to $\left(\varrho k b+\alpha b^{N}\right) /(\alpha+\varrho)$, depicted by line $w_{\infty}^{*}$ on the Figure. If $b^{N}>w^{H}$, none of the wage offers are accepted and the $w_{s}^{*}(b)$ curves coincide with the $w_{\infty}^{*}$ line for every $s$. At a particular $b^{N}$, it is optimal to continue search until the reservation wage is higher than $b^{N}$, i.e. the $w_{s}^{*}(b)$ curve lies above the dashed $45^{\circ}$ line in the Figure. For instance, if the social assistance is $b_{0}^{N}$, it is optimal to search given the individual has received $s-1$ shocks, but not for $s$ shocks. If social assistance is decreased to $b_{1}^{N}$, it would still be optimal to search after having received $s$ shocks. This is because $w_{s}^{*}\left(b^{N}\right)$ are increasing in $s$ for any given $b^{N}$.

\section{A.4 Proof of proposition 6}

First we establish that $q(s \mid U, \tau)$ is log-concave, the proposition then follows immediately. In order to prove the log-concavity, we have to derive some auxiliary expressions.

We proceed as follows. Let $T_{i}$ be the time between $i-1^{\text {st }}$ and $i^{\text {th }}$ shock. We 


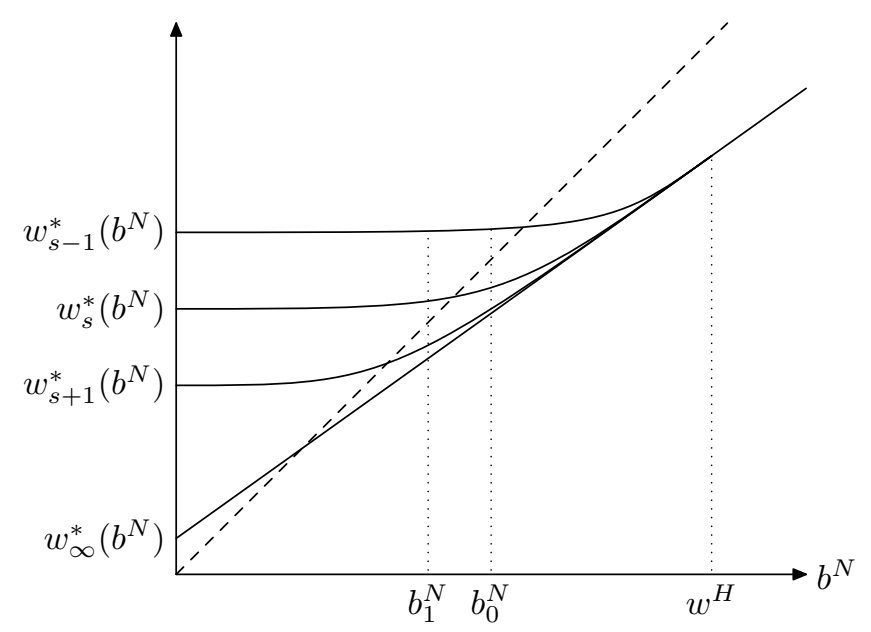

Figure 4: $w_{s}^{*}$ as function of $b^{N}$ for different values of $s$.

may write (16) as:

$$
\begin{gathered}
\operatorname{Pr}(U \mid v, \tau)=\underset{\substack{T_{1}, T_{2}, \ldots, T_{v} \\
v \text { shocks in the interval }[0, \tau]}}{\mathrm{E}} \operatorname{Pr}\left(U \mid v, \tau, T_{1}, T_{2}, \ldots, T_{v}\right)= \\
\int_{0}^{\tau} \int_{0}^{\tau-T_{1}} \int_{0}^{\tau-\left(T_{1}+T_{2}\right)} \ldots \int_{0}^{\tau-\sum_{1}^{v-1} T_{i}} \mathrm{e}^{-\vartheta_{0} T_{1}} \mathrm{e}^{-\vartheta_{1} T_{2}} \ldots \mathrm{e}^{-\vartheta_{v-1} T_{v}} \mathrm{e}^{-\vartheta_{v}\left(\tau-\sum^{v} T_{i}\right)} \times \\
\times \mathrm{d} F\left(T_{1}, T_{2}, \ldots, T_{v} \mid v \text { shocks in the interval }[0, \tau]\right), \quad(40)
\end{gathered}
$$

where $F(\cdot \mid \cdot)$ is the probability distribution function of $\left(T_{1}, T_{2}, \ldots, T_{v}\right)$ given that there are $v$ shocks in the interval $[0, \tau]$.

Distribution of the shocks The shocks, given the number of them in the time interval, are uniformly distributed.

It can be shown as follows: We have to find the distribution of $T_{i}$-s, given that there were $v$ of them in the interval $[0, \tau]$. Hence we can write the density of interest as

$$
\begin{aligned}
\operatorname{Pr}\left(T_{1}, \ldots, T_{v} \mid \sum^{v} T_{i} \leq \tau, \sum^{v+1} T_{i}>\tau\right)= & \\
= & \frac{\operatorname{Pr}\left(T_{1}, \ldots, T_{v}, \sum^{v} T_{i} \leq \tau, \sum^{v+1} T_{i}>\tau\right)}{\operatorname{Pr}\left(\sum^{v} T_{i} \leq \tau, \sum^{v+1} T_{i}>\tau\right)} .
\end{aligned}
$$

The denominator is simply the probability that there is $v$ shocks in the interval, it is the Poissonian probability:

$$
\operatorname{Pr}\left(\sum^{v} T_{i} \leq \tau, \sum^{v+1} T_{i}>\tau\right)=\frac{(\alpha \tau)^{v}}{v !} \mathrm{e}^{-\alpha \tau}
$$


We can write the numerator as

$$
\begin{aligned}
\operatorname{Pr}\left(T_{1}, \ldots, T_{v}, \sum^{v} T_{i} \leq \tau, \sum^{v+1} T_{i}>\tau\right)= \\
=\operatorname{Pr}\left(\sum^{v+1} T_{i}>\tau \mid T_{1}, \ldots, T_{v}, \sum^{v} T_{i} \leq \tau\right) \operatorname{Pr}\left(T_{1}, \ldots, T_{v}\right) .
\end{aligned}
$$

As the shocks arrive at Poissonian rate the time intervals between the shocks, $T_{i}$-s, are independent draws from the exponential distribution $\mathcal{E}(\alpha)$. Hence

$$
\operatorname{Pr}\left(T_{1}, \ldots, T_{v}\right)=\alpha \mathrm{e}^{-\alpha T_{1}} \alpha \mathrm{e}^{-\alpha T_{2}} \ldots \alpha \mathrm{e}^{-\alpha T_{v}}=\alpha^{s} \mathrm{e}^{-\alpha \sum^{v} T_{i}} .
$$

For $v+1$-th shock we have analogously

$$
\operatorname{Pr}\left(\sum^{v+1} T_{i} \mid T_{1}, \ldots, T_{v}\right)=\alpha \mathrm{e}^{-\alpha\left(\sum^{v+1} T_{i}-\sum^{v} T_{i}\right)}
$$

Now we need

$$
\operatorname{Pr}\left(\sum^{v+1} T_{i}>\tau \mid T_{1}, \ldots, T_{v}, \sum^{v} T_{i} \leq \tau\right)=\operatorname{Pr}\left(\sum^{v+1} T_{i}>\tau \mid T_{1}, \ldots, T_{v}\right)
$$

Because $\left(T_{1}, \ldots, T_{v}\right)$ implies $\sum^{v} T_{i} \leq \tau$ and hence the probability (46) is equal to

$$
\int_{\tau}^{\infty} \operatorname{Pr}\left(\sum^{v+1} T_{i} \mid T_{1}, \ldots, T_{v}\right) \mathrm{d}\left(\sum^{v+1} T_{i}\right)=\mathrm{e}^{-\alpha\left(\tau-\sum^{v} T_{i}\right)}
$$

Putting the pieces together we get

$$
\operatorname{Pr}\left(T_{1}, \ldots, T_{v}, \sum^{v} T_{i} \leq \tau, \sum^{v+1} T_{i}>\tau\right)=\mathrm{e}^{-\alpha\left(\tau-\sum^{v} T_{i}\right)} \alpha^{v} \mathrm{e}^{-\alpha \sum^{v} T_{i}}=\alpha^{v} \mathrm{e}^{-\alpha \tau}
$$

and finally

$$
\operatorname{Pr}\left(T_{1}, \ldots, T_{v} \mid \sum^{v} T_{i} \leq \tau, \sum^{v+1} T_{i}>\tau\right)=\frac{v !}{\tau^{v}} .
$$

This is uniform distribution on the feasible set as it does not depend on $T_{1}, \ldots, T_{v}$.

Recurrent structure of the $\operatorname{Pr}(U, v \mid \tau) \quad$ Now we can write (40) as

$$
\begin{aligned}
& \operatorname{Pr}(U \mid v, \tau)=\frac{v !}{\tau^{v}} \int_{0}^{\tau} \int_{0}^{\tau-T_{1}} \int_{0}^{\tau-\left(T_{1}+T_{2}\right)} \ldots \\
& \ldots \int_{0}^{\tau-\sum_{1}^{v-1} T_{i}} \mathrm{e}^{-\vartheta_{0} T_{1}} \mathrm{e}^{-\vartheta_{1} T_{2}} \ldots \mathrm{e}^{-\vartheta_{v-1} T_{v}} \mathrm{e}^{-\vartheta_{v}\left(\tau-\sum^{v} T_{i}\right)} \mathrm{d} T_{v} \mathrm{~d} T_{v-1} \ldots \mathrm{d} T_{1} .
\end{aligned}
$$

Hence, $\operatorname{Pr}(U, v \mid \tau)$ can be written using recurrent integrals as

$$
\operatorname{Pr}(U, v \mid \tau)=\operatorname{Pr}(U \mid v, \tau) \operatorname{Pr}(v \mid \tau)=\alpha^{v} \mathrm{e}^{-\left(\alpha+\vartheta_{v}\right) \tau} I_{v}^{1}(\tau)
$$


where

$$
\begin{aligned}
I_{v}^{1}(\tau) & =\int_{0}^{\tau} \mathrm{e}^{-\left(\vartheta_{0}-\vartheta_{v}\right) T_{1}} I_{v}^{2}\left(\tau-T_{1}\right) \mathrm{d} T_{1} \\
& \cdots \\
I_{v}^{i}\left(\tau_{i-1}\right) & =\int_{0}^{\tau_{i-1}} \mathrm{e}^{-\left(\vartheta_{i-1}-\vartheta_{v}\right) T_{i}} I_{v}^{i+1}\left(\tau_{i-1}-T_{i}\right) \mathrm{d} T_{i} \\
& \cdots \\
I_{v}^{v}\left(\tau_{v-1}\right) & =\int_{0}^{\tau_{v-1}} \mathrm{e}^{-\left(\vartheta_{v-1}-\vartheta_{v}\right) T_{v}} \mathrm{~d} T_{v} .
\end{aligned}
$$

Here $\tau_{j}=\tau-\sum^{j} T_{i}$.

The last integral may be written as

$$
I_{v}^{v}\left(\tau_{v-1}\right)=A_{v, 0}^{v}+A_{v, 1}^{v} \mathrm{e}^{-\left(\vartheta_{v-1}-\vartheta_{v}\right) \tau_{v-1}}
$$

where $A_{v, 0}^{v}=-A_{v, 1}^{v}=1 /\left(\vartheta_{v-1}-\vartheta_{v}\right)$. It is easy to show by induction that in general,

$$
I_{v}^{l}\left(\tau_{l-1}\right)=\sum_{i=0}^{v-l+1} A_{v, i}^{l} \mathrm{e}^{-\left(\vartheta_{v-i}-\vartheta_{v}\right) \tau_{l-1}}
$$

where the coefficients can be found using the following recurrent formula:

$$
\begin{aligned}
& A_{v, i}^{l-1}=A_{v, i}^{l} \frac{1}{\vartheta_{l-2}-\vartheta_{v-i}} \quad i \in\{0 \ldots v-l\} \\
& A_{v, l}^{l-1}=-\sum_{i=0}^{l-1} A_{v, i}^{l-1}
\end{aligned}
$$

where $l \in\{2 \ldots v\}$.

Log-concavity of $q(s \mid U, \tau) \quad$ Log-concavity of $q(s \mid U, \tau)$ follows from the logconcavity of $\operatorname{Pr}(U, v \mid \tau)$. We prove it here for $\bar{s}=2$, the general result can be shown analogously.

By definition of log-concavity we need to show that

$$
\operatorname{Pr}(U, 1 \mid \tau)^{2}-\operatorname{Pr}(U, 0 \mid \tau) \operatorname{Pr}(U, 2 \mid \tau)>0 .
$$

Let $d_{0}=\left(\vartheta_{0}-\vartheta_{1}\right) \tau$ and $d_{1}=\left(\vartheta_{1}-\vartheta_{2}\right) \tau$. Now we may write using (56)

$$
\begin{aligned}
& I_{1}^{1}(\tau)=\tau \frac{1}{d_{0}}\left(1-\mathrm{e}^{-d_{0}}\right) \\
& I_{2}^{1}(\tau)=\tau^{2} \frac{1}{d_{1}}\left[\frac{1}{d_{0}+d_{1}}-\frac{1}{d_{0}} \mathrm{e}^{-d_{1}}+\left(\frac{1}{d_{0}}-\frac{1}{d_{0}+d_{1}}\right) \mathrm{e}^{-d_{0}-d_{1}}\right] .
\end{aligned}
$$

This yields

$$
\operatorname{Pr}(U, 1 \mid \tau)^{2}-\operatorname{Pr}(U, 0 \mid \tau) \operatorname{Pr}(U, 2 \mid \tau)=\mathrm{e}^{2(\alpha-s \log \alpha)} \frac{\tau^{2}}{d_{0}^{2} d_{1}\left(d_{0}+d_{1}\right)} \mathrm{e}^{-2 \vartheta_{0} \tau} \mathrm{e}^{d_{0}} V,
$$

where $V$ equals

$$
V=d_{1}\left[d_{0}\left(\mathrm{e}^{d_{0}}-1\right)-d_{1}\left(1-\mathrm{e}^{-d_{0}}\right)\right]+d_{1}^{2}\left(\mathrm{e}^{d_{0}}-1\right)-d_{0}^{2}\left(\mathrm{e}^{d_{1}}-1\right) .
$$


The third term of the expression above is clearly negative, moreover, as $d_{1}$ is sufficiently larger than $d_{0}$, that term will dominate the $V$ and hence it will be negative. However, it is straightforward to show that $V>0$ if $d_{0}>d_{1}$ (though it is not a necessary condition). Hence $q(s \mid U, \tau)$ is log-concave if $\vartheta_{1}-\vartheta_{2}<\vartheta_{0}-\vartheta_{1}$.

The effect of $\bar{s}$ on $\vartheta^{N} \quad$ From (19) we have

$$
\vartheta^{N}(\tau ; \bar{s})=\alpha \frac{\operatorname{Pr}(\bar{s}, U \mid \tau)}{\operatorname{Pr}(U \mid \tau)}=\alpha \frac{\operatorname{Pr}(\bar{s}, U \mid \tau)}{\sum_{s=0}^{\bar{s}} \operatorname{Pr}(s, U \mid \tau)}
$$

It is easy to show that $\vartheta(\tau ; \bar{s})$ is decreasing in $\bar{s}$ given $q(\cdot)$ is $\log$ concave.

Let $\bar{s}_{1}<\bar{s}_{2}$. We have

$$
\begin{array}{r}
\vartheta^{N}\left(\tau ; \bar{s}_{1}\right)-\vartheta^{N}\left(\tau ; \bar{s}_{2}\right)=\alpha \frac{\operatorname{Pr}\left(\bar{s}_{1}, U \mid \tau\right)}{\sum_{s=0}^{\bar{s}_{1}} \operatorname{Pr}(s, U \mid \tau)}-\alpha \frac{\operatorname{Pr}\left(\bar{s}_{2}, U \mid \tau\right)}{\sum_{s=0}^{\bar{s}_{2}} \operatorname{Pr}(U \mid \tau)}= \\
=\alpha \frac{\operatorname{Pr}\left(\bar{s}_{1}, U \mid \tau\right) \sum_{s=0}^{\bar{s}_{2}} \operatorname{Pr}(s, U \mid \tau)-\operatorname{Pr}\left(\bar{s}_{2}, U \mid \tau\right) \sum_{s=0}^{\bar{s}_{1}} \operatorname{Pr}(s, U \mid \tau)}{\sum_{s=0}^{\bar{s}_{2}} \operatorname{Pr}(U \mid \tau) \sum_{s=0}^{\bar{s}_{1}} \operatorname{Pr}(s, U \mid \tau)}
\end{array}
$$

The numerator of the equation above can be written as

$$
\begin{aligned}
\sum_{s=0}^{\bar{s}_{1}}\left[\operatorname{Pr}\left(\bar{s}_{1}, U \mid \tau\right) \operatorname{Pr}\left(s+\bar{s}_{2}-\bar{s}_{1}, U \mid \tau\right)\right. & \left.\operatorname{Pr}\left(\bar{s}_{2}, U \mid \tau\right) \operatorname{Pr}(s, U \mid \tau)\right]+ \\
& +\sum_{s=0}^{\bar{s}_{2}-\bar{s}_{1}-1} \operatorname{Pr}\left(\bar{s}_{1}, U \mid \tau\right) \operatorname{Pr}(s, U \mid \tau) .
\end{aligned}
$$

The second sum is clearly positive. The first sum can be written as

$$
\sum_{s=0}^{\bar{s}_{1}} \operatorname{Pr}\left(\bar{s}_{1}, U \mid \tau\right) \operatorname{Pr}(s, U \mid \tau)\left[\frac{\operatorname{Pr}\left(s+\bar{s}_{2}-\bar{s}_{1}, U \mid \tau\right)}{\operatorname{Pr}(s, U \mid \tau)}-\frac{\operatorname{Pr}\left(\bar{s}_{1}+\bar{s}_{2}-\bar{s}_{1}, U \mid \tau\right)}{\operatorname{Pr}\left(\bar{s}_{1}, U \mid \tau\right)}\right]
$$

which is non-negative by the property of log-concave distribution (An, 1996, proposition 10).

\section{B Numerical simulation}

\section{B.1 Technical notes}

We specify the shock-specific arrival rate as $\lambda_{s}=d^{s} \lambda_{0}$. The value of $1 / d$ can be regarded as the shock strength. The simulation requires solving of (9) taking into account the fact that after the next shock it may be optimal to either continue search or to leave the labour market. We first solve (9) for $s=1$ and subject to the individual leaving the labour market in the next period $\left(w_{s+1}^{*}<b^{N}\right)$. Now we calculate $w_{s+1}^{*}$ subject to the corresponding condition in the next period and in this way check if the condition above was true. We continue until we have found $\bar{s}$ subject to $w_{\bar{s}+1}^{*}<b^{N}$. Now we solve the equation for (9) backwards, starting from period $\bar{s}$. 
Finding $\vartheta_{s}^{E}$ is straightforward. In order to find observed hazard rate, one needs to calculate the probabilities $\operatorname{Pr}(s, U \mid \tau)$. In this way it is straightforward to calculate the probability $q(s \mid U, \tau)$ numerically. Because the expression (55) involves differences of large numbers, the value of $\bar{s}$ above 10 led to numerical problems. We adjusted the process by decreasing the shock rate $\alpha$ and increasing the shock strength $1 / d$.

\section{B.2 Sensitivity analysis}

The main simulation was run using the following parameters: $\varrho=0.05, \alpha=0.2$, $d=0.5, \lambda_{0}=0.35, k=0.35, \delta=0.01, \gamma=0.01$. Table 2 gives the main indicators (employment- and unemployment rate) for the original simulation and several modifications. As $\delta$ and $\gamma$ have only a role in describing the movements out from employment and non-participation, they have no impact on the hazard rates and related variables, we do not present the related analysis here. Note also that we present the results here for given reforms, i.e. we do not attempt to constract a most efficient reform here. That excercise would require introducing a welfare measure which is beyond the scope of this paper.

\begin{tabular}{llcccccccc}
\hline \hline & $\begin{array}{l}\text { Reform: } \\
\text { deviation }\end{array}$ & \multicolumn{2}{c}{ original } & \multicolumn{2}{c}{$\mathrm{R} 1$} & \multicolumn{2}{c}{$\mathrm{R} 2$} & \multicolumn{2}{c}{$\mathrm{R} 3$} \\
& $e$ & $u$ rate & $e$ & $u$ rate & $e$ & $u$ rate & $e$ & $u$ rate \\
\hline a) & - & 0.820 & 0.070 & 0.794 & 0.064 & 0.882 & 0.072 & 0.863 & 0.068 \\
b) & $\varrho=0.01^{*}$ & 0.823 & 0.103 & 0.827 & 0.101 & 0.882 & 0.099 & 0.867 & 0.096 \\
c) & $\alpha=0.6$ & 0.486 & 0.073 & 0.487 & 0.063 & 0.539 & 0.078 & 0.531 & 0.073 \\
d) & $d=0.3^{*}$ & 0.697 & 0.067 & 0.706 & 0.065 & 0.753 & 0.071 & 0.762 & 0.069 \\
e) & $k=0.4^{*}$ & 0.815 & 0.072 & 0.825 & 0.069 & 0.911 & 0.076 & 0.860 & 0.069 \\
f) & $\lambda_{0}=0.15$ & 0.568 & 0.129 & 0.539 & 0.110 & 0.678 & 0.147 & 0.632 & 0.134 \\
\hline \hline
\end{tabular}

Table 2: Sensitivity of the main results with respect to the model parameters. ${ }^{*}$ denotes the cases where reforms do not affect the critical number of shocks, i.e. $\bar{s}_{\text {orig }}=\bar{s}_{R 1}$.

As expected, $u$ rate will fall after $\mathrm{R} 1$ in all simulations. In most cases (except for the case $\mathrm{f}$ ) $e$ increases slightly. However, for 3 of the 5 modifications listed (cases b, d and e), R1 does not affect $\bar{s}$ and hence we do not observe the effect of composition change. For the case c, $\alpha=0.6$ (increase in shock arrival rate), the motivation effect dominates the composition effect event though $\bar{s}$ changes. However, in all the cases R2 is much more efficient than R1 in order to boost employment rate. Though, in most cases it leads to an increase in open unemployment rate. The combined reform R3 has in most cases favorable indicators. However, for the cases $\mathrm{d}\left(d=0.3\right.$, i.e. strong shocks) and $\mathrm{f}\left(\lambda_{0}=\right.$ 0.15 , i.e. low offer arrival rate) the reform leads to an increase in unemployment rate. This is because of the composition effect (low social security benefits deter the weak unemployed from leaving the labour force) dominates the motivation effect.

Although the results vary, the main message remains robust: Lower unemployment benefits decrease the unemployment rate but this is not the most efficient way in order to boost participation. In order to increase participation, one has to make non-participation less attractive. 


\section{References}

Addison, J. T., And P. Portugal (2003): "Unemployment Duration: Competing and Defective Risks," Journal of Human Resources, 38(1), 146-191.

An, M. Y. (1996): "Log-concave Probability Distributions: Theory and Statistical Testing," Working Paper 96-01, CLS, Science Park Aarhus, Gustav Wieds Vej 10C, 8000 Aarhus C, Denmark.

Atkinson, A. B., And J. Micklewright (1991): "Unemployment Compensation and Labor Market Transitions: A Critical Review," Journal of Economic Literature, 29(4), 1679-1727.

Bover, O., M. Arellano, and S. Bentolila (2002): "Unemployment duration, benefit duration and the business cycle," The Economic Journal, 112, 223-265.

Burdett, K., N. M. Kiefer, D. T. Mortensen, and G. Neumann (1984): "Earnings, Unemployment, and the Allocation of Time Over Time," Review of Economic Studies, LI, 559-578.

Dooley, D., J. Fielding, And L. Levi (1996): "Health and Unemployment," Annual Review of Public Health, 17, 449-465.

Dooley, D., J. Prause, and K. A. Ham-Rowbottom (2000): "Underemployment and Depression: Longitudinal Relationships," Journal of Health and Social Behaviour, 41, 421-436.

Fredriksson, P., And B. Holmlund (2001): "Optimal unemployment insurance in search equilibrium," Journal of Labour Economics, 19, 370-399.

FriJters, P., and B. VAn der KlaAuw (2003): "Job Search with Nonparticipation," Unpublished paper, Free University Amsterdam.

Goldsmith, A. H., J. R. Veum, and W. Darity, JR. (1995): "Are being unemployed and being out of the labour force distinct states?: A psychological approach," Journal of Economic Psychology, 16, 275-295.

JAHODA, M. (1981): "Work, Employment and Unemployment: Values, Theories and Approaches in Social Research," American Psychologist, 36, 184-191.

(1982): Employment and Unemployment, The psychology of social issues. Cambridge University Press, Cambridge.

(1988): "Economic Recession and Mental Health: Some Conceptual Issues," Journal of Social Issues, 44, 13-23.

McFadyen, R. G., and J. P. Thomas (1997): "Economic and Psychological Models of Job Search Behavior of the Unemployed," Human Relations, 50, 1461-1484.

MEyer, B. D. (1990): "Unemployment insurance and unemployment spells," Econometrica, 58(4), 757-782. 
Micklewright, J., and G. NAGy (1999): "Living standards and incentives in transition: the implications of UI exhaustion in Hungary," Journal of Public Economics, 73, 297-319.

RøED, K., and T. Zhang (2003): "Does Unemployment Compensation Affect Unemployment Duration?," The Economic Journal, 113, 190-206.

Theodossiou, I. (1998): "The effects of low-pay and unemployment on psychological well-being: a logistic regression approach," Journal of Health Economics, 17, 85-104.

Toomet, O. (2005): "Regional variations in unemployment duration and discouragement probability," Ph.D. thesis, Aarhus University, Dept. of Economics, Building 322, Universitetsparken, 8000 Århus C, Denmark, Chapter 1.

VAN DEN BerG, G. J. (1990a): "Nonstationarity in Job Search Theory," The Review of Economic Studies, 57(2), 255-277.

(1990b): "Search Behaviour, Transitions to Non-participation and the Duration of Unemployment," The Economic Journal, 100, 842-865.

(1994): "The Effects of Changes of the Job Offer Arrival Rate on the Duration of Unemployment," Journal of Labour Economics, 12(3), 478-498.

WARR, P. (1987): Work, Unemployment, and Mental Healt. Oxford University Press.

Winkelmann, L., and R. Winkelmann (1998): "Why Are the Unemployed So Unhappy? Evidence from Panel Data," Economica, 65, 1-15. 